\title{
Potato production by using different potassium rates and vermi-wash spray applications
}

\author{
Mohamed A. ABDRABBO ${ }^{1,2}$, Z. Y. MAHARIK ${ }^{1}$, A. A. FARAG ${ }^{1}$, M. ABUL-SOUD ${ }^{1}$, M.A. FAHIM ${ }^{1}$ \\ Received September 04, 2019; accepted June 17, 2019. \\ Delo je prispelo 04. september 2019, sprejeto 17. junija 2019.
}

Potato production by using different potassium rates and vermi-wash spray applications

Abstract: The use of vermi-wash as organic source and potassium nutrients were investigated under this study. A field experiment was carried out during two successive summer seasons of 2017 and 2018 under open field conditions in Dokki experimental location, Agricultural Research Center, Giza Governorate, Egypt. The study aimed to evaluate the effect of applying different potassium rates 140, 280 and $420 \mathrm{~kg} \mathrm{~K}_{2} \mathrm{O}$ per hectare combined with spray vermi-wash for two, four, six times as well as spray water (control) on vegetative growth, yield of potato (Solanum tuberosum 'Spunta'). The applications of potassium rates and vermi-wash sprays affected significantly the potato vegetative growth, total and marketable tuber yield as well as nutrient contents $(\mathrm{N}, \mathrm{P}$ and $\mathrm{K} \%$ ) of potato leaves. Increasing potassium rate from 140 to $280 \mathrm{~kg} \mathrm{~K} 2 \mathrm{O}$ per hectare enhanced total yield. Increasing potassium application to $420 \mathrm{~kg} \mathrm{~K}_{2} \mathrm{O}$ per hectare led to decrease the vegetative growth and productivity compared to $280 \mathrm{~kg} \mathrm{~K}_{2} \mathrm{O}$ per hectare. Regarding the vermi-wash spray applications, data revealed that two times spray of vermiwash enhanced vegetative growth and productivity, while increasing spraying of vermi-wash to more than two times led to decrease of potato vegetative growth and productivity.

Key words: potato; water use efficiency; evapotranspiration; tuber and vegetative growth
Pridelava krompirja $\mathrm{z}$ uporabo različnih količin kalijevih gnojil in pršenja $\mathrm{z}$ izvlečki glistin deževnikov (vermi-wash)

Izvleček: V raziskavi je bila preučevana uporaba vermivoša kot organskega vira in kalijevih gnojil. Poljski poskus je bil izveden v dveh zaporednih poletnih sezonah, 2017 in 2018 na poskusni postaji v Dokki, Kmetijskega raziskovalnega centra v Gizi, Egypt. Namen raziskave je bil ovrednotiti učinke uporabe različnih odmerkov kalijevih gnojil, 140, 280 in $420 \mathrm{~kg} \mathrm{~K}_{2} \mathrm{O}_{\text {ha }}^{-1}$ v kombinaciji z 1-,2-,3-,4- in 6-kratnim pršenjem $z$ vermivošem in pršenjem $\mathrm{z}$ vodo kot kontrolo na vegetativno rast in pridelek krompirja (Solanum tuberosum 'Spunta'). Uporaba odmerkov kalijevih gnojil in pršenje $\mathrm{z}$ vermivošem sta značilno vplivala na vegetativno rast kropmpirja, na celokupni in tržni pridelek gomoljev kot tudi na vsebnost hranil (N, P in K \%) v listih krompirja. Povečanje odmerka kalija iz 140 na $280 \mathrm{~kg} \mathrm{~K}_{2} \mathrm{O}$ ha $^{-1}$ je povečalo celokupni pridelek. Nadalnje povečanje odmerkov kalija na $420 \mathrm{~kg} \mathrm{~K}_{2} \mathrm{O}$ ha $^{-1}$ je zmanjšalo vegetativno rast in produktivnost v primerjavi z odmerkom $280 \mathrm{~kg} \mathrm{~K}_{2} \mathrm{O} \mathrm{ha}{ }^{-1}$. Glede pršenja $\mathrm{z}$ vermivošem so rezultati pokazali, da je dvakratno pršenje pospešilo vegetativno rast in produktivnost, več kot dvakratna uporaba pa je oba parametra zmanjšala.

Ključne besede: krompir; učinkovitost izrabe vode; evapotranspiracija; gomolji in vegetativna rast

1 Central Laboratory for Agricultural Climate, Agricultural Research Center, Dokki 12411, Giza- Egypt

2 Corresponding author, e-mail: abdrabbo@yahoo.com 


\section{INTRODUCTION}

Potato is one of the most important foods and cash crops cultivated worldwide under a wide range of climatic condition. At present it is the fourth most important food crop in terms of its production in the world, after wheat, rice and maize FAO (2008). It is a source of both food and income in many of the densely populated areas. Because of this double purpose, the potato crop plays an important role in the improvement of rural livelihood system of many countries (Gildemacher, 2012). To match the increase of the global food demand the crop production should increase by better efficiency use of water, land and nutrients (Tilman et al., 2011).

Potassium $(\mathrm{K})$ is an essential plant nutrient that plays a very important role in plant growth and development. Its role is essential in photosynthesis, increasing enzyme activity, improving synthesis of protein, carbohydrates and fats, translocation of photosynthetic, enabling host's ability to resist, pests and diseases. Potassium is a major osmotically active cation of plant cell (Mehdi et al., 2007). The size of tubers depends on the application of potassium fertilizers due to the function of $\mathrm{K}$ in plants. The increase of tuber size is also effected by the combination of nitrogen $(\mathrm{N})$, phosphorus $\left(\mathrm{P}_{2} \mathrm{O}_{5}\right)$ and high dosage of organic manure (Davenport et al 1999). $\mathrm{K}$ also contributes to various aspects of tuber quality. The balance between nitrogen and potassium supply is of particular importance (Abd El-Latif et al., 2011). It is proposed that the amount of $\mathrm{K}$ fertilizer recommended need to be correlated to the amount of $\mathrm{K}$ removed by the tubers at harvest. From 4 to $8 \mathrm{~kg}$ of $\mathrm{K}$ per ton of tubers is removed from soil (equivalent of 5 to $8 \mathrm{~kg} \mathrm{~K}_{2} \mathrm{O} \mathrm{t}^{-1}$ ) (Potash Development Association 1997). However, a major function of $\mathrm{K}$ within the plant is osmotic regulation (Marschner, 1995) and it is therefore possible that the larger yield response to $\mathrm{K}$ in dry conditions is due to enhanced tolerance of water stress. In a sery of experiments it was indicated that tuber yields were smaller in soils with small $\mathrm{K}$ reserves compared to soils with larger $\mathrm{K}$ reserves irrespective of the amount of $\mathrm{K}$ fertilizer applied (Gunadi, 2009).

Vermi-wash, a foliar spray, is a liquid organic fertilizer collected after the passage of water through a column of worm activation. It is a collection of excretory and secretory products of earthworms, along with major recycled micronutrients of the soil and soil organic molecules that are useful for plants. These are transported to the leaf, shoots and other parts of the plants in the natural ecosystem. Vermi-wash, if collected properly, is a clear and transparent, pale yellow colored fluid according to the material for feeding the earthworms (Ismail, 1997).

Vermi-wash seems to possess an inherent property of acting not only as a fertilizer but also as a mild biocide (Pramoth, 1995). Vermi-wash is a rich source of macro and micronutrients so it acts as a suitable medium for various beneficial microbes such as $\mathrm{N}_{2}$ fixers and phosphate solubilizing bacteria (Chattopadhyay, 2014). So, the application of the vermi-wash into the soil significantly influences the biogeochemical cycles of nitrogen and phosphorus with the help of these beneficial microbes. The objective of this study is to determine the effects of different potassium rates and application of vermi-wash on growth and yield of potato.

\section{MATERIALS AND METHODS}

The current study was carried out at Dokki experimental location, Agricultural Research Center, Giza Governorate, during the first week of February of the 2017 and 2018 seasons. The Dokki Experimental Location is located at latitude $30.05^{\circ} \mathrm{N}$ and longitude $31.20^{\circ} \mathrm{E}$.

\subsection{PLANT MATERIALS}

Tuber seeds of potato (Solanum tuberosum 'Spunta') were cut and treated with fungicide and exposed for indirect light for 10 days before planting which was done on the $2^{\text {nd }}$ and $5^{\text {th }}$ of February 2017 and 2018, respectively. The plant spacing was $50 \mathrm{~cm}$ in the row and $80 \mathrm{~cm}$ between the rows. The vegetative growth of potato tuber seeds started after 2 to 3 weeks from cultivation. Plot area was $10 \mathrm{~m}$ length and $3.6 \mathrm{~m}$ width (five beds).

\subsection{THE FIELD EXPERIMENT}

The potassium treatments comprised three rates 140, 280 and $420 \mathrm{~kg} \mathrm{~K}{ }_{2} \mathrm{O}$ per hectare. During soil preparation $60 \mathrm{~K}_{2} \mathrm{O}$ units per hectare was added to the experimental soil using potassium sulphate; the rest of potassium quantity was applied by fertigation using potassium sulphate also. Plants were irrigated using drippers of $41 \mathrm{ha}^{-1}$ capacity. The total amount of irrigation water was almost 7000 cubic meter per hectare during the season. The fertigation was programmed four times weekly.

For producing vermi-wash, vertical indoor fattening trays was used. Plastic boxes ( 32 boxes arranged in two stands (4 shelves/ stand)) while a plastic tank laid in the bottom to collect the vermi-wash during the vermicomposting process. Each plastic box $(38 \times 54 \times 20 \mathrm{~cm})$ was contained $100 \mathrm{~g}$ of epigic earthworm (Lumbricus rubellus Hoffmeister, 1843 (red earthworm), Eisenia fetida (Savigny, 1826) (tiger worm), Perionyx excavatus Perrier, 1872 
Table 1: The chemical composition (ppm) of vermi-wash at $2 \mathrm{dS} \mathrm{m}^{-1}$

\begin{tabular}{|c|c|c|c|c|c|c|c|c|c|c|c|c|}
\hline & \multicolumn{6}{|c|}{ Macronutrients } & \multicolumn{2}{|c|}{ Micronutrients } & \multicolumn{4}{|c|}{ Heavy metals } \\
\hline & $\mathrm{N}$ & $\mathrm{P}$ & $\mathrm{K}$ & $\mathrm{Ca}$ & $\mathrm{Mg}$ & $\mathrm{Fe}$ & $\mathrm{Mn}$ & $\mathrm{Zn}$ & B & $\mathrm{Cu}$ & $\mathrm{Pb}$ & $\mathrm{Cd}$ \\
\hline Vermi-wash & 198 & 103 & 312 & 104 & 87 & 14.5 & 6.4 & 2.3 & 1.2 & 0.4 & n.d & n.d \\
\hline
\end{tabular}

n.d $=$ not detected

(indian blue) and Eudrilus eugeniae Kinberg, 1867 (african night crawler)) in the begening of vermicomposting process. Mixing the different raw materials: kitchen wastes (vegetables and fruits wastes) + rabbit manure in a rate of $1: 1(v / v)$ was done before feeding earthworm. The vermi-wash was collected weakly according to the vermicomposting process (Abul-Soud et al., 2009).

Vermi-wash spray solution was prepared by adding the stocked vermi-wash to tap water till electrical conductivity reach $2 \mathrm{dS} \mathrm{m}^{-1}$. The application of vermi-wash started 2 weeks after potato emergence. There was one week interval between each spray event. Control treatment was a spray by using tap water only. The electrical conductivity of tap water was $360 \mathrm{ppm}$. Through vermicomposting process for both seasons, average chemical composition of vermi-wash was estimated as illustrated in Table (1).

The physical and chemical properties of the experimental soil determined before cultivation are presented in Table 2. The chemical analysis was determined according to Chapman and Pratt (1961). The field capacity $\%(\mathrm{FC})$, wilting point $\%$ (WP) and bulk density $\mathrm{g} \mathrm{cm}^{-3}$ (BD) of the soil were determined according to Israelsen \& Hansen (1962).

\subsection{MEASUREMENTS}

Samples of three plants of each experimental plot were taken 55 days from planting, to determine growth parameters: plant height $(\mathrm{cm})$, number of leaves per plant and canopy fresh mass. Canopy dry mass was determined after oven-drying the samples at $70{ }^{\circ} \mathrm{C}$ for 48 hours. The yield components were measured at the end of the season as follows: tubers mass (g/plant) as well as marketable yield (tubers $>35 \mathrm{~mm}$ ).

For element analysis of leaves (\% N, P and $\mathrm{K}$ ), three plant samples of each plot were dried at $70{ }^{\circ} \mathrm{C}$ in an air forced oven for $48 \mathrm{~h}$. Dried leaves were digested in $\mathrm{H}_{2} \mathrm{SO}_{4} / \mathrm{H}_{2} \mathrm{O}_{2}$ mixture according to the method described by Allen (1974). Total nitrogen was determined by Kjeldahl method according to the procedure described by FAO (1980). Phosphorus content was determined using spectrophotometer according to Watanabe and Olsen (1965). Potassium content was determined photo-metrically using Flame photometer as described by Chapman and Pratt (1961).

Analysis of data was performed by computer, using SAS program for statistical analysis. The differences among means for all traits were tested for significance at 0.05 alpha level according to Waller and Duncan (1969).

\section{RESULTS}

\subsection{THE EFFECT OF POTASSIUM RATES AND VERMI-WASH ON POTATO VEGETATIVE GROWTH}

The effect of different potassium rates and vermiwash applications on vegetative growth characters (plant height, number of leaves, fresh and dry mass per plant) is illustrated in Table 2. Increasing $\mathrm{K}$ level led to the increase of potato vegetative growth up to $280 \mathrm{~kg} \mathrm{~K}_{2} \mathrm{O}$ per hectare. Increase of $\mathrm{K}$ to $420 \mathrm{~kg} \mathrm{~K}_{2} \mathrm{O}$ per hectare didn't leed to in-

Table 2: Chemical and physical analyses of the soil at experimental site

\begin{tabular}{|c|c|c|c|c|c|c|c|c|c|c|}
\hline \multirow[t]{2}{*}{ Soil depth } & \multicolumn{10}{|c|}{ Chemical properties } \\
\hline & \multicolumn{3}{|l|}{$\mathrm{ECe}$} & \multicolumn{2}{|l|}{$\mathrm{Ca}^{++}$} & $\mathrm{Mg}^{++}$ & $\mathrm{Na}^{+}$ & $\mathrm{K}^{+}$ & $\mathrm{HCO}_{3}^{-}$ & $\mathrm{CL}^{-}$ \\
\hline & \multicolumn{2}{|c|}{ mmohs $\mathrm{cm}^{-1}$} & $\mathrm{pH}$ & \multicolumn{2}{|l|}{$\mathrm{mg} \mathrm{l}^{-1}$} & $\mathrm{mg} \mathrm{l}^{-1}$ & $\mathrm{mg} \mathrm{l}^{-1}$ & $\mathrm{mg} \mathrm{l}^{-1}$ & $\mathrm{mg} \mathrm{l}^{-1}$ & $\mathrm{mg} \mathrm{l}^{-1}$ \\
\hline & \multicolumn{2}{|l|}{2.83} & 7.55 & \multicolumn{2}{|l|}{5.15} & 1.86 & 8.76 & 5.56 & 3.45 & 10.9 \\
\hline & \multicolumn{10}{|c|}{ Physical properties } \\
\hline & Sand $\%$ & & & & Silt \% & Texture & SP \% & FC $\%$ & WP \% & $\mathrm{BD} \mathrm{g} \mathrm{cm}^{3}$ \\
\hline $0-30 \mathrm{~cm}$ & 10.7 & 81 & & & 7.7 & Clay & 22.6 & 33.0 & 17.0 & 1.23 \\
\hline
\end{tabular}


Table 3: Effect of potassium rates and vermi-wash spray application on vegetative growth of potato during 2017 and 2018 seasons

\begin{tabular}{|c|c|c|c|c|c|c|c|c|c|c|}
\hline & \multicolumn{5}{|l|}{2017} & \multicolumn{5}{|l|}{2018} \\
\hline & \multicolumn{5}{|c|}{ Spray vermi-wash } & \multicolumn{5}{|c|}{ Spray vermi-wash } \\
\hline & \multicolumn{10}{|c|}{ Plant height $(\mathrm{cm})$} \\
\hline $\mathrm{K}_{2} \mathrm{O}$ level $\left(\mathrm{kg} \mathrm{ha}^{-1}\right)$ & 2 times & 4 times & 6 times & control & Mean & 2 times & 4 times & 6 times & control & Mean \\
\hline 140 & $37.7 \mathrm{f}$ & $38.8 \mathrm{e}$ & $31.5 \mathrm{i}$ & $32.5 \mathrm{~h}$ & $35.1 \mathrm{C}$ & $41.5 \mathrm{e}$ & $39.6 \mathrm{f}$ & $28.6 \mathrm{j}$ & $30.0 \mathrm{i}$ & $34.9 \mathrm{C}$ \\
\hline 280 & $46.6 \mathrm{a}$ & $45.8 \mathrm{~b}$ & $39.5 \mathrm{e}$ & $41.0 \mathrm{~d}$ & $43.2 \mathrm{~A}$ & $49.6 \mathrm{a}$ & $47.9 \mathrm{~b}$ & $40.4 \mathrm{f}$ & $42.4 \mathrm{e}$ & $45.1 \mathrm{~A}$ \\
\hline 420 & $46.4 \mathrm{ab}$ & $44.9 \mathrm{c}$ & $36.3 \mathrm{~g}$ & $37.8 \mathrm{f}$ & $41.4 \mathrm{~B}$ & $46.8 \mathrm{c}$ & $45.6 \mathrm{~d}$ & $34.2 \mathrm{~h}$ & $36.2 \mathrm{~g}$ & $40.7 \mathrm{~B}$ \\
\hline \multirow[t]{2}{*}{ Mean } & $43.6 \mathrm{~A}$ & $43.2 \mathrm{~B}$ & $35.8 \mathrm{D}$ & $37.1 \mathrm{C}$ & & $46.0 \mathrm{~A}$ & $44.4 \mathrm{~B}$ & $34.4 \mathrm{D}$ & $36.2 \mathrm{C}$ & \\
\hline & \multicolumn{10}{|c|}{ No. of leaves/plant } \\
\hline $\mathrm{K}_{2} \mathrm{O}$ level $\left(\mathrm{kg} \mathrm{ha}^{-1}\right)$ & 2 times & 4 times & 6 times & control & Mean & 2 times & 4 times & 6 times & control & Mean \\
\hline 140 & $36.5 \mathrm{~h}$ & $39.3 \mathrm{~g}$ & $30.3 \mathrm{j}$ & $32.9 \mathrm{i}$ & $34.8 \mathrm{C}$ & $34.3 \mathrm{~g}$ & $37.4 \mathrm{f}$ & 27.0 & $29.8 \mathrm{~h}$ & $32.1 \mathrm{C}$ \\
\hline 280 & $60.5 \mathrm{a}$ & $53.9 \mathrm{~b}$ & $48.3 \mathrm{~d}$ & $51.9 \mathrm{c}$ & $53.7 \mathrm{~A}$ & $58.0 \mathrm{a}$ & $52.4 \mathrm{~b}$ & $43.9 \mathrm{~d}$ & $47.9 \mathrm{c}$ & $50.6 \mathrm{~A}$ \\
\hline 420 & $47.5 \mathrm{~d}$ & $43.8 \mathrm{e}$ & $33.2 \mathrm{i}$ & $42.8 \mathrm{f}$ & $41.8 \mathrm{~B}$ & $45.4 \mathrm{~d}$ & $41.8 \mathrm{e}$ & $29.5 \mathrm{~h}$ & $38.8 \mathrm{f}$ & $38.9 \mathrm{~B}$ \\
\hline \multirow[t]{2}{*}{ Mean } & $48.2 \mathrm{~A}$ & $45.7 \mathrm{~B}$ & $37.3 \mathrm{D}$ & $42.5 \mathrm{C}$ & & $45.9 \mathrm{~A}$ & $43.9 \mathrm{~B}$ & $33.5 \mathrm{D}$ & $38.8 \mathrm{C}$ & \\
\hline & \multicolumn{10}{|c|}{ Canopy fresh mass (g/plant) } \\
\hline $\mathrm{K}_{2} \mathrm{O}$ level $\left(\mathrm{kg} \mathrm{ha}^{-1}\right)$ & 2 times & 4 times & 6 times & control & Mean & 2 times & 4 times & 6 times & control & Mean \\
\hline 140 & $201.3 \mathrm{gh}$ & $215.1 \mathrm{f}$ & $181.1 \mathrm{j}$ & $195.7 \mathrm{i}$ & $198.3 \mathrm{C}$ & $195.9 \mathrm{~h}$ & $219.6 \mathrm{~g}$ & $174.3 \mathrm{j}$ & $177.5 \mathrm{i}$ & $191.8 \mathrm{C}$ \\
\hline 280 & $334.5 \mathrm{a}$ & $295.1 \mathrm{~b}$ & $288.3 c$ & 290.2 c & $302.0 \mathrm{~A}$ & $331.4 \mathrm{a}$ & $306.9 \mathrm{~b}$ & $267.1 \mathrm{~d}$ & $286.0 \mathrm{c}$ & $297.9 \mathrm{~A}$ \\
\hline 420 & $262.3 \mathrm{~d}$ & $239.7 \mathrm{e}$ & $198.0 \mathrm{hi}$ & $206.7 \mathrm{fg}$ & 226.7 B & $259.7 \mathrm{~d}$ & $244.6 \mathrm{e}$ & $193.4 \mathrm{~h}$ & $231.8 \mathrm{f}$ & $232.4 \mathrm{~B}$ \\
\hline \multirow[t]{2}{*}{ Mean } & $266.0 \mathrm{~A}$ & $250.0 \mathrm{~B}$ & $222.5 \mathrm{D}$ & $230.9 \mathrm{C}$ & & $262.3 \mathrm{~A}$ & $257.0 \mathrm{~B}$ & $211.6 \mathrm{D}$ & $231.8 \mathrm{C}$ & \\
\hline & \multicolumn{10}{|c|}{ Canopy dry mass (g/plant) } \\
\hline $\mathrm{K}_{2} \mathrm{O}$ level $\left(\mathrm{kg} \mathrm{ha}^{-1}\right)$ & 2 times & 4 times & 6 times & control & Mean & 2 times & 4 times & 6 times & control & Mean \\
\hline 140 & $24.3 \mathrm{~g}$ & $25.9 \mathrm{f}$ & $21.8 \mathrm{j}$ & $23.1 \mathrm{i}$ & $23.8 \mathrm{C}$ & $23.6 \mathrm{~h}$ & $26.5 \mathrm{~g}$ & $19.8 \mathrm{j}$ & $21.4 \mathrm{i}$ & $22.8 \mathrm{C}$ \\
\hline 280 & $40.3 \mathrm{a}$ & $35.5 \mathrm{~b}$ & $34.7 \mathrm{c}$ & $34.6 \mathrm{c}$ & $36.4 \mathrm{~A}$ & $39.9 \mathrm{a}$ & $37.0 \mathrm{~b}$ & $32.2 \mathrm{~d}$ & $34.4 \mathrm{c}$ & $35.9 \mathrm{~A}$ \\
\hline 420 & $31.6 \mathrm{~d}$ & $28.9 \mathrm{e}$ & $23.8 \mathrm{~h}$ & $24.2 \mathrm{~g}$ & $28.4 \mathrm{~B}$ & $31.3 \mathrm{~d}$ & $29.4 \mathrm{e}$ & $26.8 \mathrm{~g}$ & $27.8 \mathrm{f}$ & $28.8 \mathrm{~B}$ \\
\hline Mean & $32.0 \mathrm{~A}$ & $30.1 \mathrm{~B}$ & $26.8 \mathrm{D}$ & $27.3 \mathrm{C}$ & & $31.6 \mathrm{~A}$ & $31.0 \mathrm{~B}$ & $26.2 \mathrm{D}$ & $27.9 \mathrm{C}$ & \\
\hline
\end{tabular}

crease the vegetative growth compared to $280 \mathrm{~kg} \mathrm{~K} 2 \mathrm{O}$ per hectare. The lowest vegetative growth was obtained using the lowest $\mathrm{K}$ level treatment $\left(140 \mathrm{~kg} \mathrm{ha}^{-1}\right)$ during the two studied seasons.

As for potato plant height, number of leaves, and canopy fresh and dry mass per plant under studied vermi-wash spray applications, differences among the treatments were significant. Increasing number of spray events from two to six led to the decrease in vegetative growth at both studied seasons. The highest vegetative growth was obtained by two times vermi-wash sprays followed by four times; while the control (without vermi-wash spray) came as the third best option; six times vermi-wash spray gave the lowest vegetative growth.

There were significant differences among the interaction effect between different potassium rates and vermi-wash spray applications. The highest vegetative growth was obtained by $280 \mathrm{~kg} \mathrm{~K}_{2} \mathrm{O} \mathrm{ha}^{-1}$ combined with two spray times followed by $280 \mathrm{~kg} \mathrm{~K}_{2} \mathrm{O} \mathrm{ha}{ }^{-1}$ combined with four spray times; the lowest vegetative growth was obtained by $140 \mathrm{~kg} \mathrm{~K}_{2} \mathrm{O} \mathrm{ha}^{-1}$ without vermi-wash spray application.

\subsection{THE EFFECT OF POTASSIUM RATES AND VERMI-WASH ON POTATO TUBER YIELD}

Regarding potato tubers yield, differences among the potassium rate treatments were significant Table 3. The highest total potato yield was obtained by $280 \mathrm{~kg} \mathrm{~K}_{2} \mathrm{O}$ hectare $^{-1}$ followed by $420 \mathrm{~kg} \mathrm{~K}_{2} \mathrm{O}$ hectare $^{-1}$ and $60 \mathrm{~kg} \mathrm{~K}_{2} \mathrm{O}$ hectare $^{-1}$ during the two successive seasons. There were no significant differences between $420 \mathrm{~kg} \mathrm{~K}_{2} \mathrm{O}$ hectare $^{-1}$ and $140 \mathrm{~kg} \mathrm{~K}_{2} \mathrm{O}$ hectare ${ }^{-1}$. Referring the marketable yield (tubers diameter $>35 \mathrm{~mm}$ ) data indicated that $280 \mathrm{~kg} \mathrm{~K}_{2} \mathrm{O}$ hectare $^{-1}$ followed by $420 \mathrm{~kg} \mathrm{~K}_{2} \mathrm{O}$ hectare $^{-1}$; while using $140 \mathrm{~kg} \mathrm{~K}_{2} \mathrm{O}$ hectare ${ }^{-1}$ gave the lowest potato marketable yield during the both seasons. 
Table 4: Effect of potassium rates and vermi-wash spray application on total and marketable yield of potato during 2017 and 2018 seasons

\begin{tabular}{|c|c|c|c|c|c|c|c|c|c|c|}
\hline & \multicolumn{5}{|l|}{2017} & \multicolumn{5}{|l|}{2018} \\
\hline & \multicolumn{5}{|c|}{ Spray vermi-wash } & \multicolumn{5}{|c|}{ Spray vermi-wash } \\
\hline & \multicolumn{10}{|c|}{ Potato yield kg / plant } \\
\hline $\mathrm{K}_{2} \mathrm{O}$ level $\left(\mathrm{kg} \mathrm{ha}^{-1}\right)$ & 2 times & 4 times & 6 times & control & Mean & 2 times & 4 times & 6 times & control & Mean \\
\hline 140 & $0.65 \mathrm{~b}$ & $0.65 \mathrm{~b}$ & $0.46 \mathrm{~d}$ & $0.60 \mathrm{bc}$ & $0.59 \mathrm{~B}$ & $0.61 \mathrm{~cd}$ & $0.65 \mathrm{bc}$ & $0.50 \mathrm{e}$ & $0.51 \mathrm{e}$ & $0.57 \mathrm{~B}$ \\
\hline 280 & $0.75 \mathrm{a}$ & $0.66 \mathrm{~b}$ & $0.56 \mathrm{c}$ & $0.75 \mathrm{a}$ & $0.68 \mathrm{~A}$ & $0.75 \mathrm{a}$ & $0.70 \mathrm{ab}$ & $0.61 \mathrm{~cd}$ & $0.70 \mathrm{ab}$ & $0.69 \mathrm{~A}$ \\
\hline 420 & $0.60 \mathrm{bc}$ & $0.56 \mathrm{c}$ & $0.55 \mathrm{c}$ & $0.60 \mathrm{bc}$ & $0.58 \mathrm{~B}$ & $0.60 \mathrm{~cd}$ & $0.56 \mathrm{de}$ & $0.50 \mathrm{e}$ & $0.55 \mathrm{de}$ & $0.55 \mathrm{~B}$ \\
\hline \multirow[t]{2}{*}{ Mean } & $0.67 \mathrm{~A}$ & $0.62 \mathrm{~B}$ & $0.52 \mathrm{C}$ & $0.65 \mathrm{AB}$ & & $0.65 \mathrm{~A}$ & $0.64 \mathrm{~A}$ & $0.54 \mathrm{C}$ & $0.59 \mathrm{~B}$ & \\
\hline & \multicolumn{10}{|c|}{ Marketable yield kg / plant } \\
\hline $\mathrm{K}_{2} \mathrm{O}$ level $\left(\mathrm{kg} \mathrm{ha}^{-1}\right)$ & 2 times & 4 times & 6 times & control & Mean & 2 times & 4 times & 6 times & control & Mean \\
\hline 140 & $0.50 \mathrm{~cd}$ & $0.50 \mathrm{~cd}$ & 0.40 ef & $0.40 \mathrm{f}$ & $0.45 \mathrm{C}$ & $0.51 \mathrm{~cd}$ & $0.50 \mathrm{~cd}$ & 0.40 ef & $0.36 \mathrm{f}$ & $0.44 \mathrm{C}$ \\
\hline 280 & $0.66 \mathrm{a}$ & $0.60 \mathrm{ab}$ & $0.51 \mathrm{~cd}$ & $0.66 \mathrm{a}$ & $0.61 \mathrm{~A}$ & $0.70 \mathrm{a}$ & $0.61 \mathrm{~b}$ & $0.51 \mathrm{~cd}$ & $0.60 \mathrm{~b}$ & $0.61 \mathrm{~A}$ \\
\hline 420 & $0.55 \mathrm{bc}$ & 0.50 cde & $0.46 \mathrm{def}$ & $0.51 \mathrm{bcd}$ & $0.51 \mathrm{~B}$ & $0.55 \mathrm{bc}$ & $0.51 \mathrm{~cd}$ & $0.41 \mathrm{ef}$ & $0.46 \mathrm{de}$ & $0.48 \mathrm{~B}$ \\
\hline Mean & $0.57 \mathrm{~A}$ & $0.53 \mathrm{~B}$ & $0.46 \mathrm{C}$ & $0.52 \mathrm{~B}$ & & $0.59 \mathrm{~A}$ & $0.54 \mathrm{~B}$ & $0.44 \mathrm{D}$ & $0.47 \mathrm{C}$ & \\
\hline
\end{tabular}

The effect of vermi-wash spray application on potato tubers yield per plant was significant, data showed that two times spray application had the significantly higher potato yield per plant followed by four times application, control treatment came in the third option; while the lowest potato yield was obtained by six times vermi-wash spray application during the two studied seasons.

Regarding the interaction effect between potassium rate and vermi-wash spray application as presented in Table 3, the highest tuber yield per plant was obtained by $280 \mathrm{~kg} \mathrm{~K}_{2} \mathrm{O} \mathrm{ha}^{-1}$ combined with two times vermi-wash spray followed by $280 \mathrm{~kg} \mathrm{~K}_{2} \mathrm{O} \mathrm{ha}{ }^{-1}$ combined with four times vermi-wash application; while the lowest yield per plant was obtained using $140 \mathrm{~kg} \mathrm{ha}^{-1}$ combined with six times vermi-wash spray.

\subsection{THE EFFECT OF POTASSIUM RATES AND VERMI-WASH ON NUTRIENT PERCENTAGE (\%) OF POTATO LEAVES}

The effect of different $\mathrm{K}$ rate on nutrient NPK percentage of potato leaves are illustrated in Table 4. Data showed that the highest $\mathrm{N}$ and $\mathrm{P}$ percentage was obtained by $280 \mathrm{~kg} \mathrm{~K}_{2} \mathrm{O}$ hectare ${ }^{-1}$ followed by $140 \mathrm{~kg} \mathrm{~K}_{2} \mathrm{O}$ hectare ${ }^{-1}$ with the lowest $\mathrm{N}$ and $\mathrm{P}$ percentages were obtained from $420 \mathrm{~kg} \mathrm{~K}_{2} \mathrm{O}$ hectare ${ }^{-1}$. Potassium percentage had different trend: increasing potassium rate from 140 to $420 \mathrm{~kg} \mathrm{~K}_{2} \mathrm{O}$ hectare $^{-1}$ led to increase $\mathrm{K}$ percentage in potato leaves during both studied seasons.

Regarding effect of vermi-wash treatment on $\mathrm{N}, \mathrm{P}$ and $\mathrm{K}(\%)$ percentages of potato leaves, the highest NPK percentages were obtained by two times vermi-wash application, followed by four times while the lowest values were obtained by six times vermi-wash spray application during the both seasons.

Looking at the interaction effect between different potassium rates and vermi-wash spray application, $280 \mathrm{~kg} \mathrm{ha}^{-1} \mathrm{~K}_{2} \mathrm{O}$ combined with two times vermi-wash spray application had the highest values of $\mathrm{N}$ and $\mathrm{P}$ in potato leaves. The lowest measurements of $\mathrm{N}$ and $\mathrm{P}$ percentages were found at $140 \mathrm{~kg} \mathrm{~K}_{2} \mathrm{O} \mathrm{ha}^{-1}$ combined with 6 times vermi-wash application. The highest $\mathrm{K}$ percentage was obtained by $420 \mathrm{~kg} \mathrm{~K}_{2} \mathrm{O} \mathrm{ha}^{-1}$ combined with two times vermi-wash spray while the lowest $\mathrm{K}$ percentage was obtained by $140 \mathrm{~kg} \mathrm{~K}_{2} \mathrm{O} \mathrm{ha}^{-1}$ combined by six times vermi-wash spray during the both studied seasons.

\section{DISCUSSION}

The results indicate that increasing the potassium rate from 140 to $280 \mathrm{~kg} \mathrm{ha}^{-1}$ led to increase of the vegetative growth, yield parameters and $\mathrm{N}, \mathrm{P}$ and $\mathrm{K}$ contents of potato while increasing the rate of potassium up to $420 \mathrm{~kg} \mathrm{~K}_{2} \mathrm{O} \mathrm{ha}^{-1}$ had a negative effect. These results could be explained by the antagonism and synergism among the nutrients. Increase of the potassium rate up to 280 unit led to enhance nitrogen and phosphorus uptake that enhance the vegetative growth, which resulted in positive impact on potato yield. On the other hand, increase of the potassium rate up to 420 unit ha ${ }^{-1}$ inhibited the nitrogen and phosphorus uptake that resulted in decreasing the vegetative growth and yield parameters. Many evidences 
Table 5: Effect of potassium rates and vermi-wash spray application on N, P and K of potato during 2017 and 2018 seasons

\begin{tabular}{|c|c|c|c|c|c|c|c|c|c|c|}
\hline \multirow[b]{4}{*}{$\mathrm{K}_{2} \mathrm{O}$ level $\left(\mathrm{kg} \mathrm{ha}^{-1}\right)$} & \multicolumn{5}{|l|}{2017} & \multicolumn{5}{|l|}{2018} \\
\hline & \multicolumn{5}{|c|}{ Spray vermi-wash } & \multicolumn{5}{|c|}{ Spray vermi-wash } \\
\hline & \multicolumn{10}{|l|}{$\mathrm{N}$} \\
\hline & 2 times & 4 times & 6 times & control & Mean & 2 times & 4 times & 6 times & control & Mean \\
\hline 140 & $3.72 \mathrm{a}$ & $3.52 \mathrm{~b}$ & $2.61 \mathrm{~g}$ & $3.32 \mathrm{~d}$ & $3.29 \mathrm{~B}$ & $3.88 \mathrm{a}$ & $3.61 \mathrm{~b}$ & $2.36 \mathrm{~h}$ & $3.03 \mathrm{e}$ & $3.23 \mathrm{~B}$ \\
\hline 280 & $3.78 \mathrm{a}$ & $3.52 \mathrm{~b}$ & $2.80 \mathrm{f}$ & $3.42 \mathrm{c}$ & $3.38 \mathrm{~A}$ & $3.97 \mathrm{a}$ & $3.67 \mathrm{~b}$ & $2.60 \mathrm{~g}$ & $3.22 \mathrm{~d}$ & $3.35 \mathrm{~A}$ \\
\hline 420 & $3.57 \mathrm{~b}$ & $3.31 \mathrm{~d}$ & $2.41 \mathrm{~h}$ & $3.10 \mathrm{e}$ & $3.10 \mathrm{C}$ & $3.67 \mathrm{~b}$ & $3.37 c$ & $2.17 \mathrm{i}$ & $2.82 \mathrm{f}$ & $3.03 \mathrm{C}$ \\
\hline \multirow[t]{2}{*}{ Mean } & $3.70 \mathrm{~A}$ & $3.43 \mathrm{~B}$ & $2.60 \mathrm{D}$ & $3.27 \mathrm{C}$ & & $3.83 \mathrm{~A}$ & $3.57 \mathrm{~B}$ & $2.40 \mathrm{D}$ & $3.00 \mathrm{C}$ & \\
\hline & \multicolumn{10}{|l|}{$\mathrm{P}$} \\
\hline $\mathrm{K}_{2} \mathrm{O}$ level $\left(\mathrm{kg} \mathrm{ha}^{-1}\right)$ & 2 times & 4 times & 6 times & control & Mean & 2 times & 4 times & 6 times & control & Mean \\
\hline 140 & $0.54 \mathrm{c}$ & $0.46 \mathrm{~d}$ & $0.38 \mathrm{~g}$ & $0.44 \mathrm{e}$ & $0.46 \mathrm{~B}$ & $0.55 \mathrm{c}$ & $0.47 \mathrm{~d}$ & $0.35 \mathrm{i}$ & $0.41 \mathrm{ef}$ & $0.45 \mathrm{~B}$ \\
\hline 280 & $0.61 \mathrm{a}$ & $0.57 \mathrm{~b}$ & $0.46 \mathrm{~d}$ & $0.57 \mathrm{~b}$ & $0.55 \mathrm{~A}$ & $0.62 \mathrm{a}$ & $0.59 \mathrm{~b}$ & $0.42 \mathrm{e}$ & $0.54 \mathrm{c}$ & $0.55 \mathrm{~A}$ \\
\hline 420 & $0.38 \mathrm{~g}$ & $0.38 \mathrm{~g}$ & $0.31 \mathrm{~h}$ & $0.40 \mathrm{f}$ & $0.37 \mathrm{C}$ & $0.39 \mathrm{~g}$ & $0.40 \mathrm{fg}$ & $0.28 \mathrm{j}$ & $0.37 \mathrm{~h}$ & $0.36 \mathrm{C}$ \\
\hline \multirow[t]{2}{*}{ Mean } & $0.51 \mathrm{~A}$ & $0.47 \mathrm{~B}$ & $0.38 \mathrm{C}$ & $0.47 \mathrm{~B}$ & & $0.52 \mathrm{~A}$ & $0.49 \mathrm{~B}$ & $0.35 \mathrm{D}$ & $0.44 \mathrm{C}$ & \\
\hline & \multicolumn{10}{|l|}{ K } \\
\hline $\mathrm{K}_{2} \mathrm{O}$ level $\left(\mathrm{kg} \mathrm{ha}^{-1}\right)$ & 2 times & 4 times & 6 times & control & Mean & 2 times & 4 times & 6 times & control & Mean \\
\hline 140 & $2.82 \mathrm{~d}$ & $2.91 \mathrm{c}$ & $2.31 \mathrm{~g}$ & $2.80 \mathrm{de}$ & $2.71 \mathrm{C}$ & $3.01 \mathrm{c}$ & $2.92 \mathrm{~d}$ & $2.06 \mathrm{~h}$ & $2.61 \mathrm{f}$ & $2.65 \mathrm{C}$ \\
\hline 280 & $2.92 \mathrm{c}$ & $3.01 \mathrm{~b}$ & $2.70 \mathrm{ef}$ & $2.91 \mathrm{c}$ & $2.89 \mathrm{~B}$ & $3.12 \mathrm{~b}$ & $3.12 \mathrm{~b}$ & $2.41 \mathrm{~g}$ & $2.72 \mathrm{e}$ & $2.84 \mathrm{~B}$ \\
\hline 420 & $3.20 \mathrm{a}$ & $3.16 \mathrm{a}$ & $2.72 \mathrm{ef}$ & $3.16 \mathrm{a}$ & $3.06 \mathrm{~A}$ & $3.36 \mathrm{a}$ & $3.32 \mathrm{a}$ & $2.56 \mathrm{f}$ & $3.00 \mathrm{c}$ & $3.06 \mathrm{~A}$ \\
\hline Mean & $2.98 \mathrm{~B}$ & $3.03 \mathrm{~A}$ & $2.58 \mathrm{C}$ & $2.96 \mathrm{~B}$ & & $3.16 \mathrm{~A}$ & $3.12 \mathrm{~B}$ & $2.34 \mathrm{D}$ & $2.78 \mathrm{C}$ & \\
\hline
\end{tabular}

were obtained from well-known references on mineral nutrition of plants (Rene et al., 2017, Fageria et al., 2011, Abdrabbo et al 2010, Chien et al., 2009, White et al. 2009 Abdrabbo et al., 2005 and Epstein and Bloom 2005).

Vermi-wash contains a number of different enzymes such as proteases, amylases, urease and phosphatase (Samadhiya et al., 2013), soluble plant nutrients, organic acids and mucus of earthworms and microbes. The high macro and micronutrients contents of vermi-wash could play a role as a good foliar spray. But vermi-wash are not just about macro and micro nutrients but it contains also enzymes, plant growth hormones, secretion of earthworms which could stimulate growth and yield of crops and even develop resistance in crops. Many researchers investigated the use of vermi-wash as a foliar spray or as liquid fertilizer as well as diseases suppression and illustrated the positive impact on growth and the yield of different plants (Abul-Soud et al. 2015, Farag et al., 2014 Samadhiya et al., 2013, and Medany et al., 2003). However, most of the studies mentioned the beneficial effects of vermi-wash or vermicompost leachate produced from animal manure + earthworms or from the earthworms alone. Two times of vermi-wash spray had a positive impact on vegetative growth characteristics, yield parameters and nutrient contents compared to the control treatments. On the other hand, increase the foliar numbers to 4 or 6 times create a negative impact and decrease vegetative growth characteristics, yield parameters and nutrient contents of potato that could be explained by stress occurred on the potato plants during the hot summer seasons.

\section{CONCLUSIONS}

Increase of the potassium rate or vermi-wash sprays numbers didn't have a positive impact on vegetative growth characteristics, yield parameters or nutrient contents of potato plant. The following recommendations can be extracted from this study: the optimum potassium rate was 280 unit $\mathrm{ha}^{-1}$ while two sprays of vermi-wash produced the highest vegetative growth, yield parameters and nutrient contents of potato. Further work need to be done in the future related to effect of vermiwash on plant growth and productivity for other vegetable crops.

\section{REFERENCES}

Abd El-Latif, K. M., Osman, E. A.M., Abdullah, Abdullah, R. \& Abd El-Kader N. (2011). Response of potato plants to po- 
tassium fertilizer rates and soil moisture deficit. Advances in Applied Science Research, 2(2), 388-397.

Abdrabbo, M. A. A., Medany, M. A., Abdelmoneim. E. M. \& Abou-Hadid. A. F. (2005). Fertigation Management of Cucumber Plants Under Plastic Houses. Egyptian Journal of Horticulture, 32, 1-13.

Abdrabbo M.A.A.; Khalil, A.A., Hassanien, M.K.K. \& AbouHadid, A.F. (2010). Sensitivity of Potato Yield to Climate Change. Journal of Applied Sciences Research, 6(6), 751-755.

Abul-Soud, M., Medany M., Hassanein, M.K., Abul-Matty S.H. \& Abu-Hadid A.F. (2009). Case study: Vermiculture and vermicomposting technologies use in sustainable agriculture in Egypt. The seventh international conference of organic agriculture, Cairo, Egypt. Egyptian Journal of Agricultural Research, 87(1), 389:403.

Abul-Soud M.A., Emam M.S.A., Hawash A.H., Hassan M. \& Yahia Z. (2015). The utilize of vermicomposting outputs in ecology soilless culture of lettuce. Journal of Agriculture and Ecology Research, 5(1), 1-15. https://doi.org/10.9734/ JAERI/2016/20008

Benitez, E., Nogales, R., Elvira, C., Masciandaro, G. \& Ceccanti, B. (1999). Enzyme activities as indicators of the stabilization of sewage sludges composting with Eisenia foetida. Bioresource Technology, 67, 297-303. https://doi.org/10.1016/ S0960-8524(98)00117-5

Chien, S. H., Prochnow, L. I. \& Cantarella, H. (2009). Recent developments of fertilizer production and use to improve nutrient efficiency and minimize environmental impacts. Advances in Agronomy, 102, 267-322. https://doi. org/10.1016/S0065-2113(09)01008-6

Davenport J.R., Bentley, E.M. \& Whiteley K.M. (1999). Potassium fertilizers and potato yield and quality in the Columbia Basin. In: Proc. 38th American Washington State Potato conference and Trade shows, Moses Lake, Washington, 2-4 Feb 1999. pp. 137-143.

Epstein, E., \& Bloom, A. J. (2005). Mineral nutrition of plants: Principles and perspectives. Sunderland, MA: Sinauer.

Fageria, N. K., Baligar, V. C. \& Jones. C. A. (2011). Growth and mineral nutrition of field crops. Boca Raton, FL: CRC. https://doi.org/10.1201/b10160

Farag A. A., Abdrabbo, M. A. A. \& Abul-Soud, M. (2014). Maximizing the potato production via nitrogen fertilization and plant spacing. Arab University Journal of Agricultural Science, 22(1), 29-41. https://doi.org/10.21608/ajs.2014.14694

Gildemacher, P.R. (2012). Innovation in Seed Potato Sys- tems in Eastern Africa. $\mathrm{PhD}$ Thesis, Wageningen University, Wageningen, The Netherlands.

Gunadi, N., (2009). Response of potato to potassium fertilizer sources and application methods in andisols of west java. Indonesian Journal of Agricultural Science, 10(2), 65-72. https://doi.org/10.21082/ijas.v10n2.2009.p65-72

Ismail, S. A. (1997). Vermicology: The Biology of Earthworms. Orient longman Press, Hyderabad, pp. 92.

Marschner, H. (1995). Mineral Nutrition of Higher Plants, 2nd Edn. London: Academic Press.

Medany, M. A., Abdrabbo, M. A. A., Refaie, K. M. \& AbouHadid, A. F. (2003). Using agrometeorological data to calaculate Irrigation and fertilization requirement and scheduling for vegetable. Acta Horticulture, 608, 253-258. https:// doi.org/10.17660/ActaHortic.2003.608.31

Mehdi, S.M. Sarfaz, M. and Hafeez, M. (2007). Response of rice advance line P.B- 95 to potassium application in salinesodic soil. Pakistan Journal of Biological Science, 10, 29352939. https://doi.org/10.3923/pjbs.2007.2935.2939

Mengel, K., Kirkby, E. A., Kosegarten, H. \& Appel, T. (2001). Principles of plant nutrition. Dordrecht: Kluwer Academic Publishers. https://doi.org/10.1007/978-94-010-1009-2

Potash Development Association (1997). Phosphate and Potash Removal by Crops, leaflet 10/97. Langhorne: PDA.

Pramoth A, (1995). Vermi-wash-A potent bio-organic liquid "Ferticide". M.Sc., dissertation, University of Madras. pp, 29.

René P. J. J. Rietra, Marius Heinen, Chistian O. Dimkpa \& Prem S. B.(2017). Effects of Nutrient Antagonism and Synergism on Yield and Fertilizer Use Efficiency. Communications in Soil Science and Plant Analysis 7, 48(16), 1895-1920. https://doi.org/10.1080/00103624.2017.14074 29

Samadhiya H., Dandotiya P., Chaturvedi J. \& Agrawal O.P. (2013). Effect of vermiwash on the growth and development of leaves and Stem of tomato plants. International Journal of Current Research, 5(10), 3020-3023.

White, P. J., Bradshaw, J. E., Dale, M. F. B., Ramsay, G., Hammond, J. P. \& Broadley, M. R. (2009). Relationships between yield and mineral concentrations in potato tubers. HortScience, 44(1), 6-11. https://doi.org/10.21273/ HORTSCI.44.1.6 